\title{
Fabrication and Characterization of High-activity Pt/C Electrocatalysts for Oxygen Reduction
}

\author{
Borami Lim, Joung Woon Kim, Seung Jun Hwang, Sung Jong Yoo, Eun Ae Cho, Tae-Hoon Lim, and Soo-Kil Kim* \\ Fuel Cell Center, Korea Institute of Science and Technology, Hawolgok-dong, Sungbuk-gu, Seoul 136-791, Korea \\ *E-mail: sookilkim@kist.re.kr \\ Received January 11, 2010, Accepted April 15, 2010
}

\begin{abstract}
A $20 \mathrm{wt} \% \mathrm{Pt} / \mathrm{C}$ is fabricated and characterized for use as the cathode catalyst in a polymer electrolyte membrane fuel cell (PEMFC). By using the polyol method, the fabrication process is optimized by modifying the carbon addition sequence and precursor mixing conditions. The crystallographic structure, particle size, dispersion, and activity toward oxygen reduction of the as-prepared catalysts are compared with those of commercial $\mathrm{Pt} / \mathrm{C}$ catalysts. The most effective catalyst is obtained by ultrasonic treatment of ethylene glycol-carbon mixture and immediate mixing of this mixture with a Pt precursor at the beginning of the synthesis. The catalyst exhibits very uniform particle size distribution without agglomeration. The mass activities of the as-prepared catalyst are $13.4 \mathrm{~mA} / \mathrm{mg}_{\mathrm{Pt}}$ and $51.0 \mathrm{~mA} / \mathrm{mg}_{\mathrm{Pt}}$ at $0.9 \mathrm{~V}$ and $0.85 \mathrm{~V}$, respectively, which are about 1.7 times higher than those of commercial catalysts.
\end{abstract}

Key Words: PEMFC, Pt/C, Polyol, Oxygen reduction, Mass activity

\section{Introduction}

Polymer electrolyte membrane fuel cells (PEMFCs) have attracted considerable interest as power sources for fuel cell vehicles, residential power generation, and portable electronic devices because of their high energy density, low pollutant emission, diversity of fuels, and low operation temperature. ${ }^{1}$ However, some drawbacks such as high content of Pt catalysts and slow kinetics of fuel oxidation and oxygen reduction on the Pt catalysts ${ }^{1-3}$ need to be overcome in order to commercialize PEMFCs. In particular, the kinetics of the oxygen reduction reaction (ORR) at the cathode side is a decisive factor of PEMFC performance. Accordingly, there have been numerous researches to improve the activity of cathode catalysts, which include alloying of Pt with transition metals, shape control of Pt nanocrystals, and fabrication of $\mathrm{Pt}$ with novel nanostructures. For example, Kitchin et al. ${ }^{4}$ have demonstrated that the d-band of Pt can be modulated by interactions with subsurface metals such as $\mathrm{Fe}$ and Ni. The counterbalance of adsorption and desorption of oxygen (or oxygen-related species) can be achieved on these Pt-3d alloy surfaces, thus enhancing ORR kinetics. Greeley et al. ${ }^{5}$ plotted a volcano curve of literature-reported kinetic currents for various compositions of Pt-M alloys or layered structures, of which the $\mathrm{Pt}_{3} \mathrm{Ni}$ (111) alloy showed the highest activity. Similar to the Ptsubsurface metal alloy, M-Pt core-shell structures have been widely investigated..$^{6-9}$ Representatively, Wang et al. ${ }^{9}$ reported the effects of Pt shell thickness, lattice mismatch, and particle size on the activity of Pd-Pt and $\mathrm{Pd}_{3} \mathrm{Co}$-Pt core-shell structures. Besides the core-shell structures, various novel nanostructures of Pt have been investigated as cathode catalysts, such as nanocubes, ${ }^{10}$ nanotubes, ${ }^{11}$ and nanodendrites. ${ }^{12}$

Although the aforementioned strategies were intensively investigated recently, the fabrication and characterization of $\mathrm{Pt} / \mathrm{C}$ catalysts is still of great interest ${ }^{13-16}$ because $\mathrm{Pt} / \mathrm{C}$ catalysts are the only type of commercially available catalysts that have reliable activity and durability for PEMFC. Numerous researches have been carried out to develop new and optimized preparation methods, to characterize the physicochemical properties, and to improve the activity of $\mathrm{Pt} / \mathrm{C}$ catalysts. ${ }^{17-23}$

In this study, we attempted to fabricate high-activity $\mathrm{Pt} / \mathrm{C}$ catalysts in terms of ORR in order to apply them to the PEMFC cathode. Among the various fabrication methods of impregnation and chemical reduction, ${ }^{19,24-27}$ we used the polyol method with ethylene glycol (EG) as a reducing agent. ${ }^{18}$ The polyol method is a very simple method that does not require stabilizing agents and is effective to synthesize very small and well-dispersed metal nanoparticles. ${ }^{28}$ However, the synthesizing parameters greatly affect the characteristics of resulting catalysts, such as water-EG ratio (in the modified polyol method), ${ }^{29,30}$ concentration of $\mathrm{EG},{ }^{18}$ and solution $\mathrm{pH} .{ }^{18,30}$ It is also known that the interaction between the Pt precursor and carbon support plays a crucial role in terms of the activity and durability of fabricated $\mathrm{Pt} / \mathrm{C}$ catalysts. $^{22}$

In this study, we fabricated $20 \mathrm{w} \% \mathrm{Pt} / \mathrm{C}$ catalysts for use as a cathode in PEMFC; we used a modified polyol method and compared the obtained catalysts with commercially available catalysts. To find the best synthesis conditions for the improvement of catalyst activity, five different synthesizing procedures were used, and the interaction between the Pt precursor and/or Pt particles with carbon support, which affects the particle size, dispersion, thus the ORR activity, was examined. The as-prepared catalysts were analyzed using various spectroscopic and electrochemical analysis tools and compared with commercial catalysts.

\section{Experimental}

Catalyst synthesis. $20 \mathrm{wt} \% \mathrm{Pt} / \mathrm{C}$ catalysts were prepared by the modified polyol method using EG as the reducing agent. ${ }^{18,31}$ A mixture of $45 \mathrm{~mL} \mathrm{EG}$ and $5 \mathrm{~mL}$ water was used as the solvent. $19.51 \mathrm{mg}$ of hexachloroplatinic acid $\left(\mathrm{H}_{2} \mathrm{PtCl}_{6} 6 \mathrm{H}_{2} \mathrm{O}\right.$, Alfa Aesar) and $78 \mathrm{mg}$ of Vulcan XC-72R carbon were used as the Pt pre- 

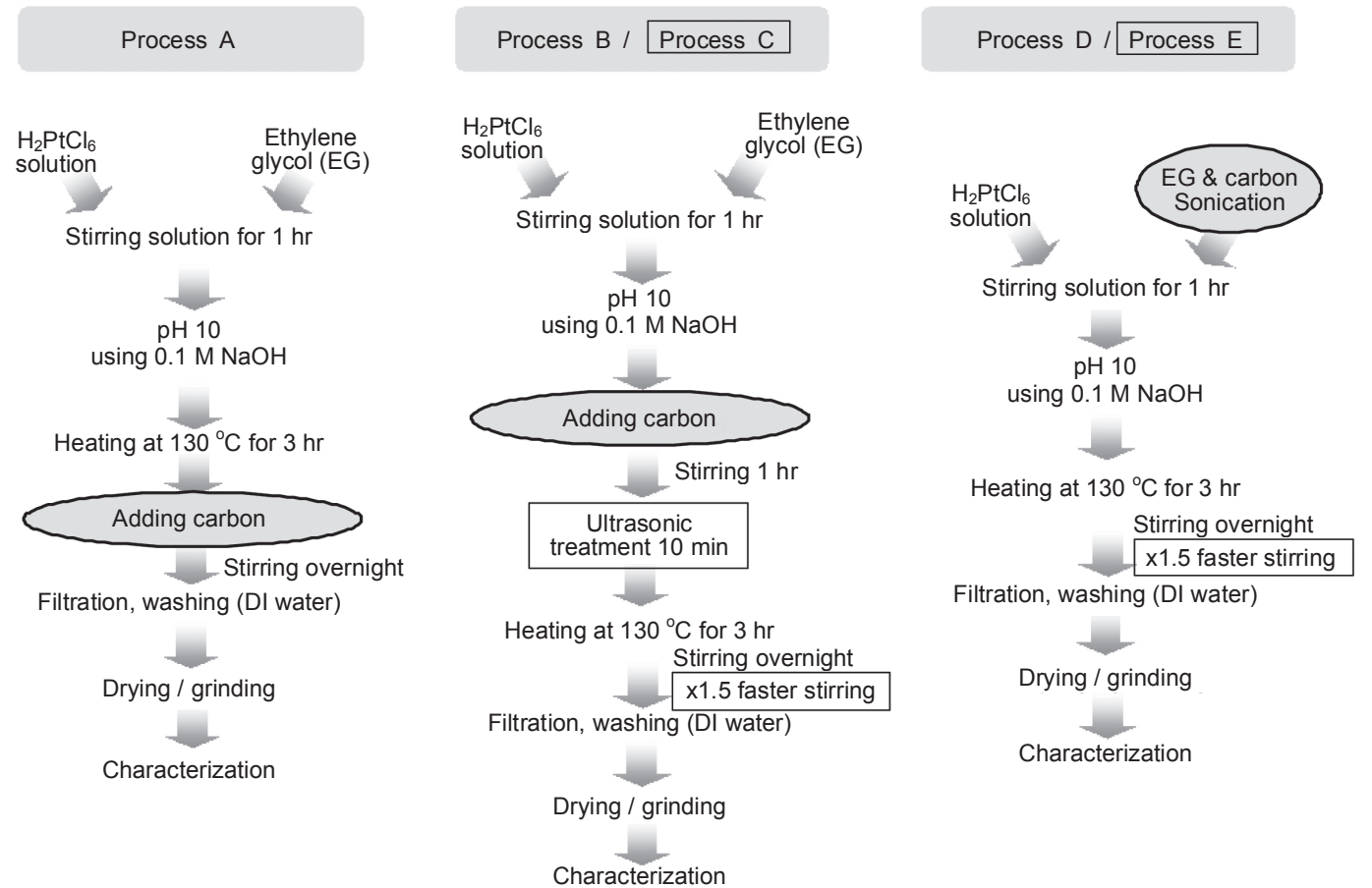

Figure 1. Experimental procedures of $20 \mathrm{wt} \% \mathrm{Pt} / \mathrm{C}$ synthesis. Processes A to E are based on the modified polyol method with different carbon addition sequences and mixing conditions.

cursor and carbon support, respectively. The Vulcan carbon has BET surface area or $234.1 \mathrm{~m}^{2} / \mathrm{g}$ and average pore diameter of $6.1 \mathrm{~nm}$, and was used as received without further purification. Since the Pt precursor is readily hydrated in air, a $0.05 \mathrm{M}$ mother solution of Pt precursor was used to add precise amounts of the precursor. Five synthesis procedures (processes A to E) differing in carbon addition conditions and mixing conditions of the starting materials were adopted. The experimental schemes are summarized in Fig. 1. The details are as follows: in process A, the Pt precursor and EG solution were mixed and stirred for $1 \mathrm{~h}$. The solution $\mathrm{pH}$ was adjusted to 10 using $0.1 \mathrm{MNaOH}$ solution. The mixture was then heated at $130{ }^{\circ} \mathrm{C}$ for $3 \mathrm{~h}$. A condenser was connected to the flask to prevent evaporation of EG during the heating step. After heating for $3 \mathrm{~h}$, the solution was cooled to room temperature and carbon was added to it. The mixture was stirred overnight and the resulting $\mathrm{Pt} / \mathrm{C}$ catalyst was filtered and washed several times using DI water and finally dried at $60{ }^{\circ} \mathrm{C}$ for $12 \mathrm{~h}$ in a dry oven. The dried powder was ground using agate and a sieve. Most of the procedures in processes $B$ and $C$ were similar to those in process $\mathrm{A}$, the only difference being that carbon was added prior to heating at $130{ }^{\circ} \mathrm{C}$ in processes $\mathrm{B}$ and $\mathrm{C}$. The differences of process $\mathrm{C}$ from process $\mathrm{B}$ were as follows: (i) ultrasonic treatment after carbon addition to the solution and (ii) more vigorous stirring during the heating and overnight stirring of the mixture. Processes D and E also followed the same procedure as in process $\mathrm{A}$, but in the processes $\mathrm{D}$ and $\mathrm{E}$, carbon was initially added to the EG solution and after sonication of the mixture for the better dispersion of carbon, Pt precursors were added to the mixture. More vigorous stirring was performed in the case of process $\mathrm{E}$.

The five different $20 \mathrm{wt} \% \mathrm{Pt} / \mathrm{C}$ catalysts prepared were analyzed and compared with commercial Johnson Matthey (JM)
$20 \mathrm{wt} \% \mathrm{Pt} / \mathrm{C}$ catalyst using various spectroscopic and electrochemical tools.

Characterization of the catalysts. The crystallographic structure, particle size, shape, and dispersion of the as-prepared catalysts were analyzed using $\mathrm{x}$-ray diffraction (XRD; Rigaku, D/MAX-2500) and a transmission electron microscope (TEM; Philips, CM30). The particle sizes calculated from XRD peak analysis were compared with those obtained by TEM. The actual amounts of Pt loaded on carbon were analyzed by inductively coupled plasma (ICP; Perkin-Elmer).

Electrochemical characterization of the as-prepared $20 \mathrm{wt} \%$ $\mathrm{Pt} / \mathrm{C}$ catalysts was carried out by conducting cyclic voltammetry (CV) and linear sweep voltammetry (LSV) of the ORR. Electrochemical analysis was performed using a conventional threeelectrode system comprising a glassy carbon (GC) working electrode, $\mathrm{Pt}$ mesh counter electrode, and an $\mathrm{Ag} / \mathrm{AgCl}$ reference electrode. Electrochemical signals were generated and measured using a potentiostat (Autolab, PGSTAT302).

Catalyst ink solutions to mount the $\mathrm{Pt} / \mathrm{C}$ catalyst on the GC electrode were prepared by mixing $7.2 \mathrm{mg}$ of the as-prepared $\mathrm{Pt} / \mathrm{C}$ catalyst, $0.1 \mathrm{~mL}$ DI water, $2.5 \mathrm{~mL}$ ethanol, $0.4995 \mathrm{~mL}$ isopropyl alcohol (IPA), and $0.5 \mu \mathrm{L}$ of $5 \mathrm{wt} \%$ Nafion solution. For $\mathrm{CV}$ analysis, $0.1 \mathrm{M} \mathrm{HClO}_{4}$ electrolyte was purged with Ar gas for $30 \mathrm{~min}$ to remove the dissolved oxygen. LSV for ORR was carried out by purging $0.1 \mathrm{M} \mathrm{HClO}_{4}$ electrolyte with oxygen for $30 \mathrm{~min}$ to obtain an oxygen-saturated electrolyte. A rotating disk electrode (RDE; Princeton Applied Research Model 616) was used in the measurement of ORR kinetics. The measured electrochemical surface areas (ESAs) and ORR activities of the five as-prepared catalysts were compared with those of the JM catalyst. 


\section{Results and Discussion}

Figure 2 shows the XRD pattern of the as-prepared catalysts and the commercial catalyst. All catalysts showed a typical facecentered cubic structure of Pt. The carbon peak was observed at $2 \theta$ of around $25^{\circ}$. The other four peaks appeared at $39.5^{\circ}$, $46.2^{\circ}, 67.5^{\circ}$, and $81.2^{\circ}$ corresponded to Pt (111), (200), (220), and (311), respectively. The intensities of the peaks have a strong dependence on the synthesis method. Among the as-prepared $\mathrm{Pt} / \mathrm{C}$ catalysts, the ones prepared using process A and process E exhibited the highest and lowest intensity, respectively. The $\mathrm{Pt} / \mathrm{C}$ catalysts prepared using processes $\mathrm{B}, \mathrm{C}$, and $\mathrm{D}$ showed moderate intensities, and the intensity of the commercial catalyst was lower than those of any of the as-prepared catalysts. The peak intensity and width have a strong relationship with average particle size. Using the well-known Debye-Scherrer formula, the average particle size for each synthesis method was calculated using (220) plane peaks, and it is summarized in Table 1. As shown in the table, the particle sizes gradually decrease from process $\mathrm{A}$ to $\mathrm{E}$. In the case of process $\mathrm{A}$, where Vulcan carbon was added after heating at $130^{\circ} \mathrm{C}$, the average particle size was about $4.9 \mathrm{~nm}$. In the case of carbon addition before heating (processes $B$ and $C$ ), the particle size was about $3.4 \mathrm{~nm}$. When carbon was added at the beginning of the synthesis (process D), i.e., with simultaneous mixing of carbon with the Pt precursor and EG solution, the average particle size was about $3.1 \mathrm{~nm}$. With more vigorous overnight stirring (process E), the particle size was further reduced to $2.6 \mathrm{~nm}$. However, the commercial catalyst exhibited the smallest particle size of $2.3 \mathrm{~nm}$. To check the exact amounts $\mathrm{Pt}$ in the as-prepare $\mathrm{Pt} / \mathrm{C}$ catalyst, ICP analysis was performed and the results are shown in Table 1 . The Pt amounts are between 20.4 and $23.5 \mathrm{wt} \%$, which are in good accordance with the predicted values. The actual weight values were further used in calculating the mass activity $\left(\mathrm{mA} / \mathrm{mgt}_{\mathrm{Pt}}\right)$ of the as-prepared catalysts.

Particle size, shape, and distribution of carbon were further investigated by TEM analysis; the results are shown in Fig. 3. In the case of process $\mathrm{A}$, where carbon was added after the reduction of the Pt precursor, the number of Pt particles on the carbon surface was very low. The particle size distribution was broad, ranging from 1 to $8 \mathrm{~nm}$, which is believed to be a result of homogeneous reduction of the Pt precursor and the weak interaction between the Pt particle and carbon. When carbon was added during synthesis, such as in processes $B$ and $C$, many more Pt particles were loaded on the carbon surface. In the case of process $\mathrm{B}$, the Pt particle size distribution had a very broad range ( 2 to $7 \mathrm{~nm}$ ), of which the highest value is believed to be due to $\mathrm{Pt}$ agglomeration. When a 10-min ultrasonic treatment was introduced after carbon addition for the purpose of better dispersion (process $\mathrm{C}$ ), an overall increase in the particle size was observed. This is probably due to the increase in surface mobility of Pt on carbon and weakening of Pt-carbon interaction by sonication.

When carbon was initially mixed with EG and the Pt precursor, Pt dispersion and particle size distribution showed a very different aspect. From the TEM images of the Pt/C catalysts prepared using processes $\mathrm{D}$ and $\mathrm{E}$, the Pt particles were found to have a size distribution ranging from 1 to $6 \mathrm{~nm}$ and many more Pt particles were found to be loaded on carbon. The sonication of

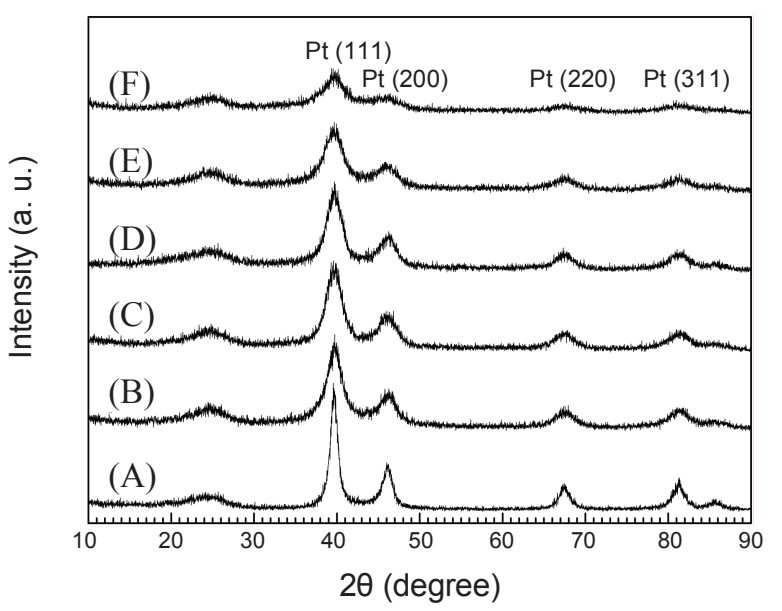

Figure 2. XRD patterns of $20 \mathrm{wt} \% \mathrm{Pt} / \mathrm{C}$ catalyst: (A) process A, (B) process $\mathrm{B},(\mathrm{C})$ process $\mathrm{C},(\mathrm{D})$ process $\mathrm{D},(\mathrm{E})$ process $\mathrm{E}$, and $(\mathrm{F})$ commercial catalyst.

Table 1. Particle sizes and wt \% of the as-prepared and commercial $\mathrm{Pt} / \mathrm{C}$ catalysts obtained from XRD and ICP analyses.

\begin{tabular}{ccc}
\hline Pt/C & Particle size $(\mathrm{nm})$ & Pt wt \% \\
\hline Process A & 4.9 & 20.4 \\
Process B & 3.4 & 21.1 \\
Process C & 3.4 & 20.8 \\
Process D & 3.1 & 23.5 \\
Process E & 2.6 & 22.6 \\
commercial & 2.3 & 19.6 \\
\hline
\end{tabular}

the carbon-EG mixture prior to the addition of the Pt precursor may have improved the homogeneity of carbon dispersion in the solution. In particular, in the case of process E, a more vigorous overnight stirring led to greater homogeneity both in the particle size and dispersion, i.e., more than $80 \%$ of Pt particles had sizes of 1.5 to $2.5 \mathrm{~nm}$ and the Pt particles were distributed on the entire carbon surface, including the edges.

The differences between making sample $\mathrm{E}$ and other samples are i) sonication of carbon and EG mixture (which differs from process A, B, C), ii) initial mixing between Pt precursor and carbon mixture (which differs with process A, B, C), and iii) vigorous mixing during the overnight stirring (which differs with process D). First, sonication may improve the dispersion of carbon. This may enlarge the solution wetting area of carbon, which resulted in the increase of number density of $\mathrm{Pt}$ on the carbon, as indicated from comparison between Fig. 3 (a c) and Fig. 3 (d e). Second, the initial mixing of Pt precursor with carbon mixture enables a precursor-carbon interaction to stabilize $\mathrm{Pt}^{2+}$ ions and strong adsorption of Pt on carbon surface, as reported in the literature. ${ }^{22}$ This may prevent the agglomeration of Pt and increase the number density of Pt on carbon. Third, from the comparison between Fig. 3 (d) and (e), vigorous overnight stirring was found to contribute to the dispersion and size uniformity.

In comparison with the commercial catalyst, the prepared catalyst using process E still maintain the superior characteristics of homogeneous dispersion and uniform particle size distribution between 1.5 to $2.5 \mathrm{~nm}$ as indicated in the histogram. 


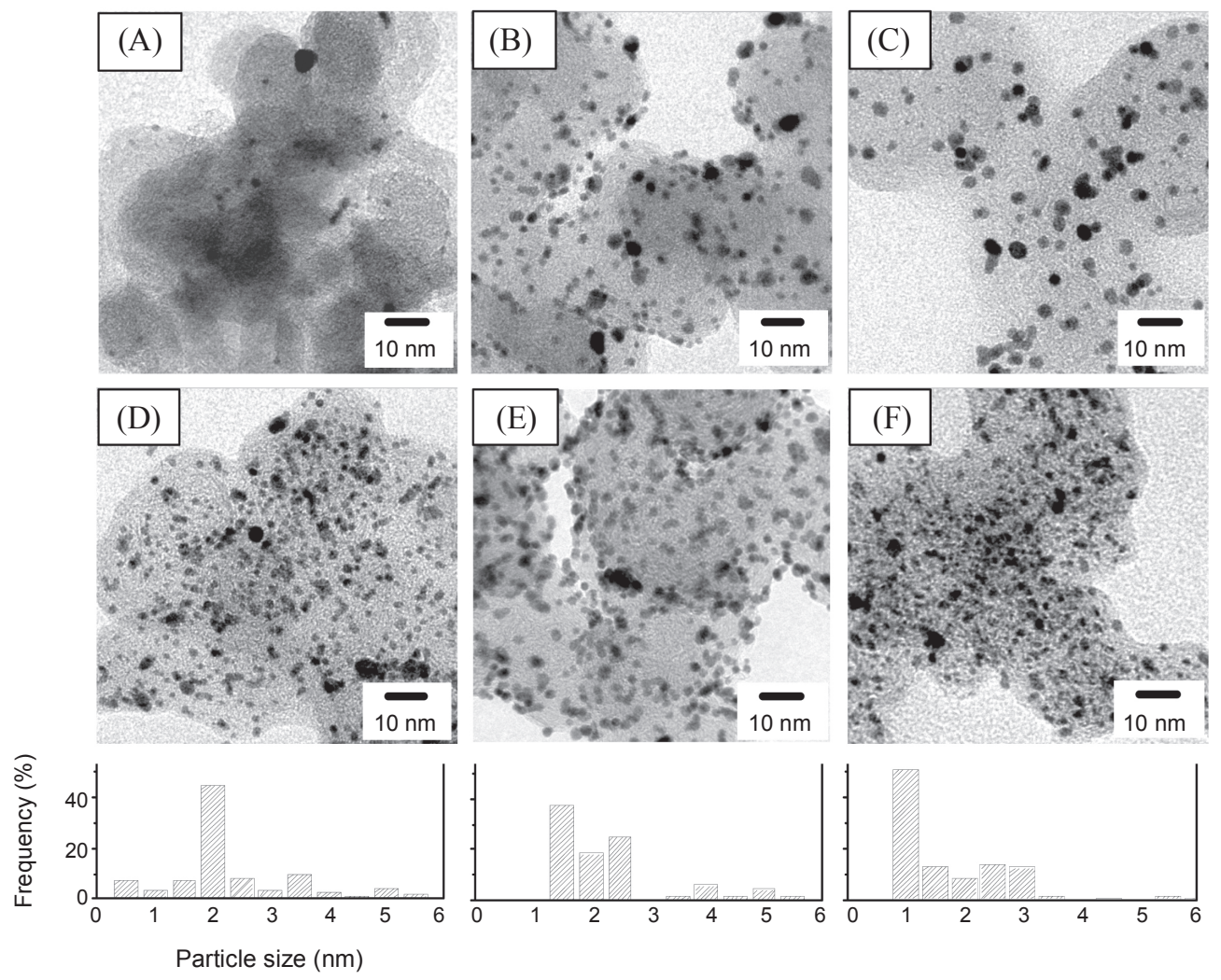

Figure 3. TEM images of $20 \mathrm{wt} \% \mathrm{Pt} / \mathrm{C}$ catalyst: (A) process $\mathrm{A}$, (B) process $\mathrm{B},(\mathrm{C})$ process $\mathrm{C}$, (D) process $\mathrm{D}$, (E) process E, and (F) commercial catalyst. Particle size distribution histograms are also provided for the sample D, E, and F.

Though the average particle size of commercial catalyst is smaller than that of the process E catalyst, the size distribution is broad ranging from 1 to $3 \mathrm{~nm}$, which enables the prospect that the process E catalyst may have the better electrochemical properties.

Figure 4 shows the cyclic voltammogram of the as-prepared and commercial $20 \mathrm{wt} \% \mathrm{Pt} / \mathrm{C}$ catalysts used to analyze ESAs. The potential was swept from 0 to $1.2 \mathrm{~V} v s$. NHE (normal hydrogen electrode) with a scan rate of $50 \mathrm{mV} / \mathrm{s}$. When the potential was swept in the negative direction, adsorption of protons on the Pt surface occurred and formed a sharp peak in the potential region from 0.25 to $0 \mathrm{~V}$. Changing the sweep to the opposite direction prior to the hydrogen evolution led to the oxidative desorption of protons from the Pt surface. The proton desorption peaks occurred in the potential range from 0 to $0.3 \mathrm{~V}$ and were used to measure the ESA. Oxidation of Pt occurs at $0.8 \mathrm{~V}$ after passing the double-layer charging region from 0.3 to $0.6 \mathrm{~V}$. The oxidized Pt is reduced during the backward sweep, producing a reduction peak at $0.65 \mathrm{~V}$. The charges passed during proton desorption are indicative of ESA, and they are calculated by integrating the corresponding desorption peak areas above the double-layer charging current. The charge values for each process are 0.28 (process A), 0.70 (process B), 0.93 (process C), 1.02 (process D), and $1.05 \mathrm{mC}$ (process $\mathrm{E}$ ), which are in good accordance with the characteristics of particle size and distribution shown in Figs. 2 and 3. In particular, the charges of the catalysts prepared using processes $\mathrm{D}$ and $\mathrm{E}$ are much larger than that of the commercial catalyst $(0.91 \mathrm{mC})$.

The activities of the as-prepared catalysts toward ORR are

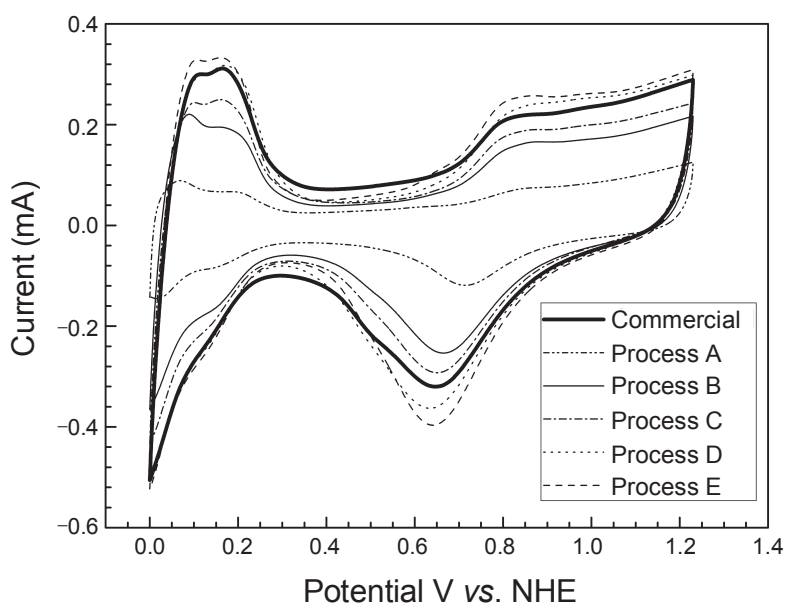

Figure 4. Cyclic voltammograms of the as-prepared and commercial $20 \mathrm{wt} \% \mathrm{Pt} / \mathrm{C}$ catalysts. Ar-purged $0.1 \mathrm{M} \mathrm{HClO}_{4}$ solution was used as the electrolyte, and the scan rate was $50 \mathrm{mV} / \mathrm{s}$.

characterized by carrying out RDE experiments, the results of which are presented in Fig. 5 (a). Oxygen-purged $0.1 \mathrm{M} \mathrm{HClO}_{4}$ electrolyte and the catalyst-coated GC electrode were used for the measurement of ORR kinetics. Potentials were recorded with respect to RHE (reversible hydrogen electrode) to facilitate comparison with literature values. As the potential was scanned from $1.2 \mathrm{~V}$ in the negative direction, ORR was initiated at around $1.0 \mathrm{~V}$. After passing through the kinetic-diffusion mixed region, 
(a)

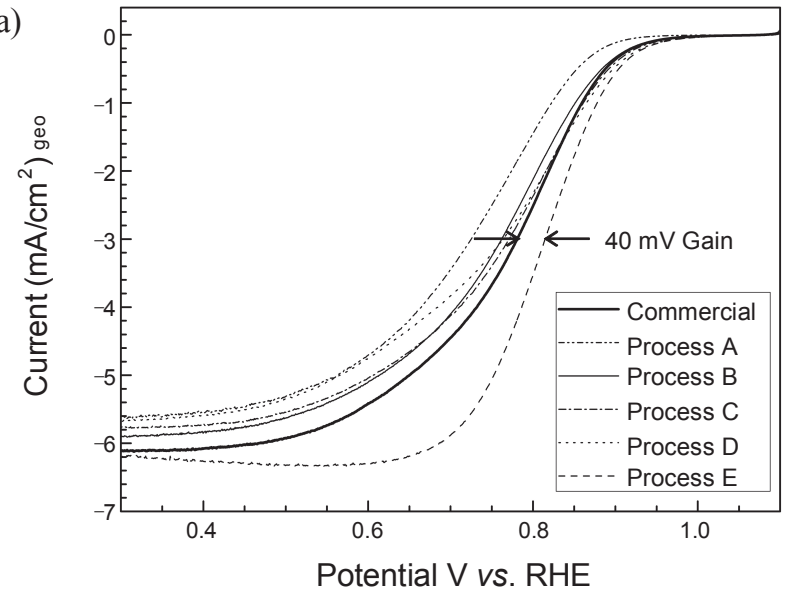

(b)

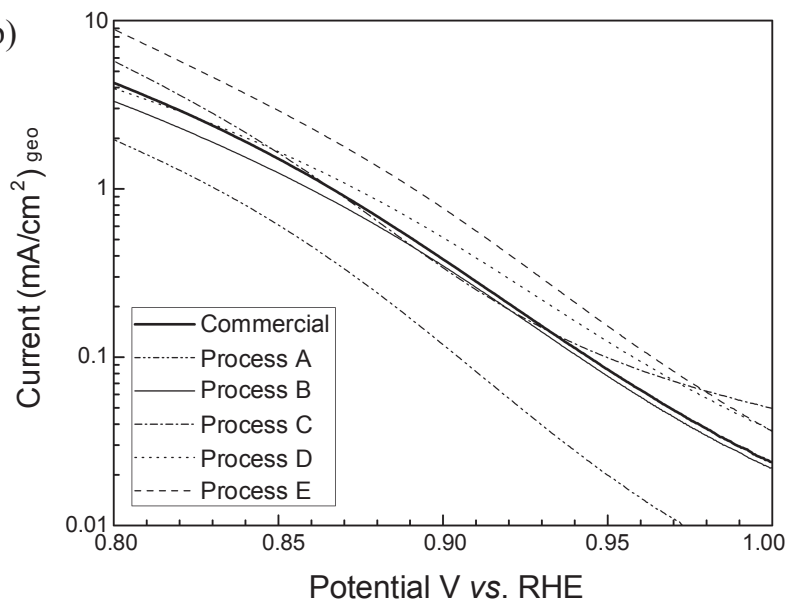

Figure 5. ORR kinetics of the as-prepared and commercial $20 \mathrm{wt} \% \mathrm{Pt} / \mathrm{C}$ catalysts. Oxygen-saturated $0.1 \mathrm{MHClO}_{4}$ solution was used as the electrolyte and the RDE was rotated at $2500 \mathrm{rpm}$ : (a) linear sweep voltammetry for ORR and (b) Tafel plot after transport current correction from (a).

(a)

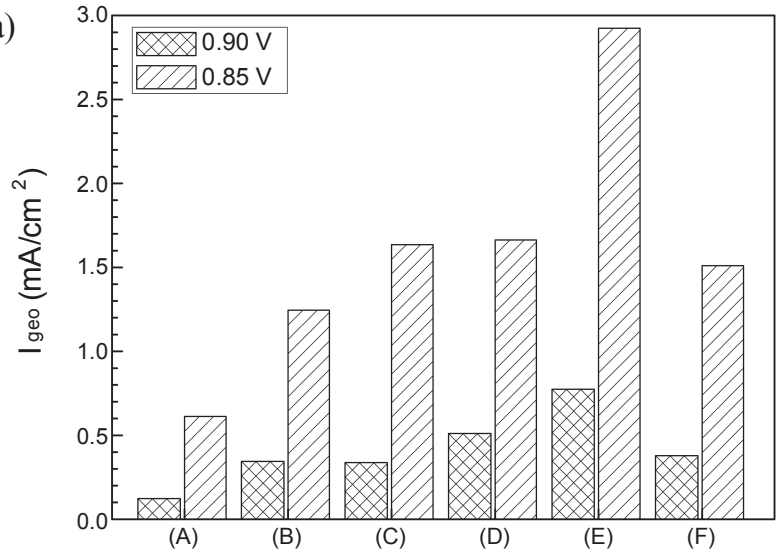

(b)

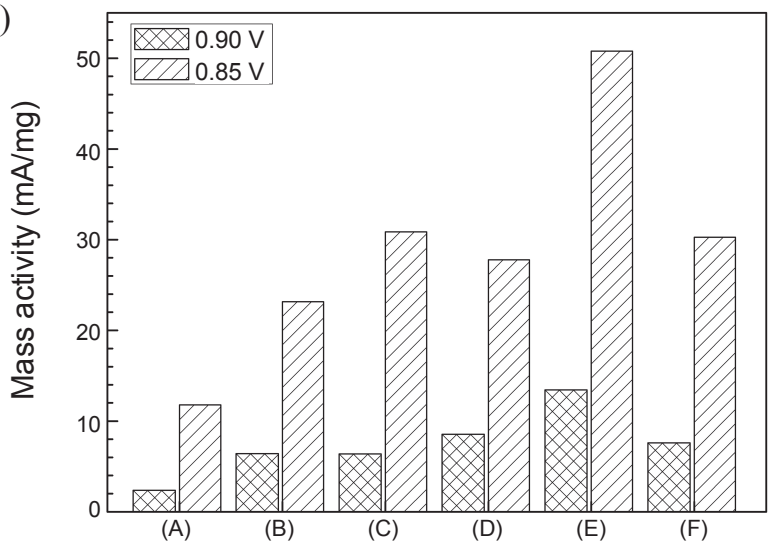

Figure 6. (a) Geometric current densities and (b) mass activities of the as-prepared and commercial $20 \mathrm{wt} \% \mathrm{Pt} / \mathrm{C}$ catalysts at $0.9 \mathrm{~V}$ and $0.85 \mathrm{~V}$ versus RHE obtained from Tafel plot and ICP analysis results: (A) process $\mathrm{A},(\mathrm{B})$ process $\mathrm{B},(\mathrm{C})$ process $\mathrm{C},(\mathrm{D})$ process $\mathrm{D}$, (E) process $\mathrm{E}$, and $(\mathrm{F})$ commercial catalyst.

the current densities reached their mass transfer limiting values of around $6 \mathrm{~mA} / \mathrm{cm}^{2}$. For the precise description of the activities of the as-prepared catalysts, kinetic currents were obtained by correcting the oxygen mass transport currents using the wellknown Levich-Koutechky equation. ${ }^{32}$

$$
\frac{1}{i_{\text {measured }}}=\frac{1}{i_{\text {kinetic }}}+\frac{1}{i_{\text {diffusion }}}
$$

The Tafel plot of the transport-corrected kinetic currents in the potential range from 0.8 to $1.0 \mathrm{~V}$ is shown in Fig. 5 (b). The geometric current densities of each catalyst at $0.85 \mathrm{~V}$ and $0.9 \mathrm{~V}$ are obtained from this Tafel plot, and they are summarized in Fig. 6 (a). The $\mathrm{Pt} / \mathrm{C}$ catalyst prepared using process A showed the lowest current densities of $0.12 \mathrm{~mA} / \mathrm{cm}^{2}$ and $0.6 \mathrm{~mA} / \mathrm{cm}^{2}$ at $0.9 \mathrm{~V}$ and $0.85 \mathrm{~V}$, respectively. However, in the case of the Pt/C catalyst prepared using process $\mathrm{E}$, the current densities were $0.78 \mathrm{~mA} / \mathrm{cm}^{2}$ and $2.91 \mathrm{~mA} / \mathrm{cm}^{2}$ at $0.9 \mathrm{~V}$ and $0.85 \mathrm{~V}$, respective- ly, which are the highest values among the as-prepared catalysts and even higher than those of the commercial catalyst $(0.38 \mathrm{~mA} /$ $\mathrm{cm}^{2}$ and $1.5 \mathrm{~mA} / \mathrm{cm}^{2}$ at $0.9 \mathrm{~V}$ and $0.85 \mathrm{~V}$, respectively). As the processes changed from $\mathrm{A}$ to $\mathrm{E}$, the current densities gradually increased, which is in good accordance with the CV results shown in Fig. 4. Besides having the highest geometric current densities, the catalysts prepared using process E enabled about $40 \mathrm{mV}$ gain in the half-wave potential when compared with the commercial catalyst, as shown in Fig. 5 (a).

The mass activities of the as-prepared catalysts were calculated from the current values in Fig. 5 (b) and the ICP results. The calculated values at both 0.85 and $0.9 \mathrm{~V}$ are summarized according to the fabrication methods in Fig. 6 (b). At both potentials, the mass activities showed very similar trends with those of the geometric current densities shown in Fig. 6 (a). Although the catalysts prepared using process A exhibited the lowest mass activities of $2.4 \mathrm{~mA} / \mathrm{mg}_{\mathrm{Pt}}$ and $11.8 \mathrm{~mA} / \mathrm{mg}_{\mathrm{Pt}}$ at $0.9 \mathrm{~V}$ and $0.85 \mathrm{~V}$, respectively, the catalysts prepared using process $\mathrm{E}$ had the highest mass activities of $13.4 \mathrm{~mA} / \mathrm{mg}_{\mathrm{Pt}}$ and $50.8 \mathrm{~mA} / \mathrm{mg}_{\mathrm{Pt}}$ 
at $0.9 \mathrm{~V}$ and $0.85 \mathrm{~V}$, respectively. The mass activity values of process $\mathrm{E}$ are almost 1.7 times higher than those of the commercial catalyst $\left(7.6 \mathrm{~mA} / \mathrm{mg}_{\mathrm{Pt}}\right.$ and $30.3 \mathrm{~mA} / \mathrm{mg}_{\mathrm{Pt}}$ at $0.9 \mathrm{~V}$ and $0.85 \mathrm{~V}$, respectively). This is due to (i) small and uniform Pt particle size and (ii) better dispersion as has been discussed in the earlier section, which is ascribed to the strong interaction between $\mathrm{Pt}$ ions and carbon during the synthesis in process $\mathrm{E}$.

\section{Conclusions}

High-activity $\mathrm{Pt} / \mathrm{C}$ catalysts for ORR were fabricated using a modified polyol method. Initial mixing of Pt precursor with ultrasonic-treated EG-carbon mixture yielded the best $\mathrm{Pt} / \mathrm{C}$ catalyst in terms of particle size distribution and dispersion on the carbon supports. This is due to the strong interaction of $\mathrm{Pt}$ ions with the carbon surface. Addition of carbon at a later step of the synthesis deteriorated the properties of the catalyst. The mass activities of the $\mathrm{Pt} / \mathrm{C}$ catalyst prepared using the optimized methods are about 1.7 times higher than those of the commercial catalyst.

Acknowledgments. This work was financially supported by the Korean Ministry of Knowledge Economy (MKE) through the Korea Institute of Energy Technology Evaluation and Planning under contract number 2008-N-FC08-P-01. This work was also partially supported by a grant (M2009010025) from the Fundamental R\&D Program for Core Technology of Materials funded by MKE, Republic of Korea.

\section{References}

1. Yang, H.; Alonso-Vante N.; Léger, J.-M.; Lamy, C. J. Phys. Chem. B 2004, 108, 1938.

2. Antolini, E.; Salgado, J. R. C.; da Silva, R. M.; Gonzalez, E. R. Mater. Chem. Phys. 2007, 101, 395.

3. Santiago, E. I.; Varanda, L. C.; Villullas, H. M. J. Phys. Chem. C 2007, 111, 3146.

4. Kitchin, J. R.; Nørskov, J. K.; Barteau, M. A.; Chen, J. G. J. Chem. Phys. 2004,120, 10240.

5. Greeley, J.; Stephens, I. E. L.; Bondarenko, A. S.; Johansson, T. P.; Hansen, H. A.; Jaramillo, T. F.; Rossmeisl, J.; Chorkendorff, I.; Nørskov, J. K. Nature Chem. 2009, 1, 552.

6. Zhai, J.; Huang, M.; Dong, S. Electroanalysis 2007, 19, 506.

7. Wei, Z. D.; Feng, Y. C.; Li, L.; Liao, M. J.; Fu, Y.; Sun, C. X.; Shao,
Z. G.; Shen, P. K. J. Power Sources 2008, 180, 84

8. Koh, S.; Strasser, P. J. Am. Chem. Soc. 2007, 129, 12624.

9. Wang, J. X.; Inada, H.; Wu, L.; Zhu, Y.; Choi, Y.; Liu, P.; Zhou, W.-P.; Adzic, R. R. J. Am. Chem. Soc. 2009, 131, 17298.

10. Wang, C.; Daimon, H.; Lee, Y.; Kim, J.; Sun, S. J. Am. Chem. Soc. 2007, 129, 6974

11. Chen, Z.; Waje, M.; Li, W.; Yan, Y. Angew. Chem. Int. Ed. 2007, 46, 4060 .

12. Lim, B.; Jiang, M.; Camargo, P. H. C.; Cho, E. C.; Tao, J.; Lu, X.; Zhu, Y.; Xia, Y. Science 2009, 324, 1302.

13. Liu, S.-J.; Huang, C.-H.; Huang, C.-K.; Hwang, W.-S. Electrochem. Commun. 2009, 11, 1792.

14. Wang, Z.-B.; Zuo, P.-J.; Chu, Y.-Y.; Shao, Y.-Y.; Yin, G.-P. Int. J. Hydrogen Energy 2009, 34, 4387.

15. Nores-Pondal, F. J.; Viella, I. M. J.; Troiani, H.; Granada, M.; de Miguel, S. R.; Scelza, O. A.; Corti, H. R. Int. J. Hydrogen Energy 2009, 34, 8193.

16. Martin, A. J.; Chaparro, A. M.; Gallardo, B.; Folgado, M. A.; Daza, L. J. Power Sources 2009, 192, 14.

17. Khan, M. R.; Lin, S. D. J. Power Sources 2006, 162, 186.

18. Oh, H.-S.; Oh, J.-G.; Kim, H. J. Power Sources 2008, 183, 600.

19. Zeng, J.; Lee, J. Y.; Zhou, W. Appl. Catal. A:Gen. 2006, 308, 99.

20. Pozio, A.; Francesco, M. De.; Cemmi, A.; Cardellini, F.; Giorgi L., J. Power Sources 2002, 105, 13.

21. Shih, Y.-H.; Sagar, G. V.; Lin, S. D. J. Phys. Chem. C 2008, 112, 123.

22. Yu X.; Ye, S. J. Power Sources 2007, 172, 133.

23. Zhang, S.; Yuan, X.-Z.; Hin, J. N. C.; Wang, H.; Friedrich, K. A.; Schulze, M. J. Power Sources 2009, 194, 588.

24. Okhlopkova, L.; Lisitsyn, A.; Likholobov, V.; Gurrath, M.; Boehm, H. Appl. Catal. A: Gen. 2000, 204, 229.

25. Pai, Y.; Ke, J.; Chou, C.; Lin, J.; Zen, J.; Shieu, F. J. Power Sources 2006, 163, 398.

26. Liu, Z. L.; Liu, X. Y.; Su, X.; Lee, J. Y. J. Phys. Chem. B 2004, 108, 8234.

27. Zhou, Z. H.; Wang, S. L.; Zhou, W. J.; Wang, G. X.; Jiang, L. H.; Li, W. Z.; Song, S. Q.; Liu, J. G.; Sun, G. Q.; Xin, Q. Langmuir 2003, 3, 394

28. Watanabe, M.; Uchida, M.; Motoo, S. J. Electroanal. Chem. 1987, $229,395$.

29. Zhou, Z.; Wang, S.; Zhou, W.; Wang, G.; Jiang, L.; Li, W.; Song, S.; Liu, J.; Sun, G.; Xin, Q. Chem. Commun. 2003, 3, 394.

30. Jiang, L.; Sun, G.; Zhou, Z.; Sun, S.; Wang, Q.; Yan, S.; Li, H.; Tian, J.; Guo, J.; Zhou, B.; Xin, Q. J. Phys. Chem. B 2005, 109, 8774.

31. Li, W.; Zhou, W.; Li, H.; Zhou, Z.; Zhou, B.; Sun, G.; Xin, Q. Electrochim. Acta 2004, 49, 1045.

32. Moffat, T. P.; Mallett, J. J.; Hwang, S.-M. J. Electrochem. Soc. 2009, 156, B238. 